\title{
The multiple states of environmental DNA and what is known about their persistence in aquatic environments
}

\author{
Quentin Mauvisseau ${ }^{1}$, Lynsey Harper ${ }^{2}$, Michael Sander ${ }^{3}$, Robert H. Hanner ${ }^{4}$, Hannah \\ Kleyer $^{3}$, and Kristy Deiner ${ }^{3}$ \\ ${ }^{1}$ Natural History Museum, University of Oslo, Oslo, Norway \\ ${ }^{2}$ Nature Metrics Ltd, CABI Site, Bakeham Lane, Egham, Surrey, TW20 9TY, UK \\ ${ }^{3}$ Department of Environmental Systems Science, ETH Zurich, Switzerland \\ ${ }^{4}$ Department of Integrative Biology, University of Guelph, Canada
}

November 8, 2021

Corresponding author*: alpinedna@gmail.com and quentin.mauvisseau@gmail.com

\begin{abstract}
Increased use of environmental DNA (eDNA) analysis for indirect species detection has spurred the need to understand eDNA persistence in the environment. Understanding the persistence of eDNA is complex because it exists in a mixture of different states (e.g., dissolved, particle-adsorbed, intra-cellular and organellar), and each state is expected to have a specific decay rate that depends on environmental parameters. Thus, improving knowledge about eDNA conversion rates between states and the reactions that degrade eDNA in different states is needed. Here, we outline how water chemistry and suspended mineral particles likely affect conversion among each eDNA state and indicate how environmental parameters affect persistence of states in the water column. Based on deducing these controlling parameters, we conducted a meta-analysis of the eDNA literature to assess whether we could already derive a general understanding of eDNA states persisting in the environment. However, we found that these parameters are often not being measured or reported when measured, and in many cases very few experimental data exists from which to draw conclusions. Therefore, further study of how environmental parameters affect eDNA state conversion and eDNA decay in aquatic environments is needed. We recommend analytic controls that can be used during the processing of water to assess potential losses of different eDNA states if all were present in a water sample and outline future experimental work that would help determine the dominant eDNA states in water.
\end{abstract}

Keywords: environmental DNA, states, persistence, aquatic environments

Synopsis: eDNA is composed of dissolved, particle-adsorbed, intra-cellular and organellar DNA. We review the parameters affecting decay rates and abundance of each of these states in the water column.

\section{Introduction}

Over the last decade, the use of eDNA-based detection to monitor aquatic biodiversity in both marine and freshwater systems has rapidly increased ${ }^{1}$. The reproducibility of eDNA surveys relies on the assumption that the DNA detected provides an accurate measure of presence of the local community or targeted species at the respective point in time and space ${ }^{2,3}$. As many conservation and management strategies have now adopted 
eDNA-based surveys ${ }^{4,5}$, it is urgent to understand the various processes that influence eDNA persistence in aquatic systems so that accurate inferences of a species presence can be made from the detection of its eDNA. Indeed, previous studies highlighted that eDNA stability can vary in systems depending on many parameters, including species-specific eDNA shedding rates, seasonality, and environmental conditions ${ }^{6-8}$. When organisms shed DNA into the water column, this gives rise to extra-organismal eDNA (i.e. DNA no longer associated with its organism of origin) and can take the form of at least four states ${ }^{9,10}$. These four states include: dissolved DNA, DNA bound to the surfaces of suspended particles ${ }^{3,6,10}$, and DNA still encapsulated in either a cell or an organelle ${ }^{11}$. What we currently lack is a robust understanding of how water chemistry and other environmental parameters affect which eDNA state(s) predominate in specific aquatic environments and how they persist.

The state-of-the-art is to extract eDNA from water and target a single species or whole communities of species using a set of primers and Polymerase Chain Reaction $(\mathrm{PCR})^{12}$. However, the presence of eDNA in different states has implications for data interpretation, as detection of species might be influenced by the 'detectability' of a specific state that is the result of both the environmental parameters determining the state and the analytical workflow (i.e., preservation, capture, extraction and detection methods) used to isolate the DNA from the water column. Consequently, the relative distribution of eDNA among the different states could affect the probability of detection for a targeted species' DNA. Therefore, the currently unknown stabilities of eDNA in different states combined with the lack of information on which eDNA states are being detected creates large uncertainty for the spatial and temporal inferences that can be made from extra-organismal eDNA detection ${ }^{3,13}$. To reduce this uncertainty, we require a better understanding of the states that eDNA assumes, the processes converting eDNA between different states, and the variations in state-dependent eDNA decay rates.

In this perspective, we describe four principal states of eDNA that are likely in aquatic environments. Based on the presumed chemical behaviour of each state, we discuss how environmental parameters, such as temperature, $\mathrm{pH}$ and suspended particles, may influence the conversion of eDNA between states (e.g., ${ }^{14}$ ). We briefly review what is known about DNA decay, covered in detail elsewhere ${ }^{3,12,13}$, and summarize what has been observed from experimental studies on eDNA decay in relation to the environmental parameters of temperature and $\mathrm{pH}$. We then present the results of a literature search to ascertain what states of eDNA are likely being detected using single-species eDNA assays. Lastly, we outline a number of analytic controls, which, if used, will help to assess the loss of specific states from aquatic samples and allow for post hoc observations about the state(s) contributing to species detection. We close with suggestions for future research that would help to fill knowledge gaps regarding the space and time inference that can be made from extra-organismal eDNA species detections.

\section{Different states of eDNA}

Environmental DNA can be present in four principal states described in Figure 1. Here we focus on eukaryotic extra-organismal $\mathrm{eDNA}^{9}$, which is commonly analysed to make accurate inferences as to whether or not a targeted species (usually of conservation or management concern) or community was present at time of sampling ${ }^{16}$. Additionally, we focus on eDNA states at the cellular level and below because all eukaryotic life forms have cells as a basic unit encapsulating DNA. We recognize that extra-organismal eDNA may also originate from even more complex structures such as tissues and gametes, but variations in these structures are complex across eukaryotes and beyond the scope of what we address in this perspective. However, this variation in tissues and other structures is likely a main factor that contributes to species-specific rates of DNA degradation and persistence. 


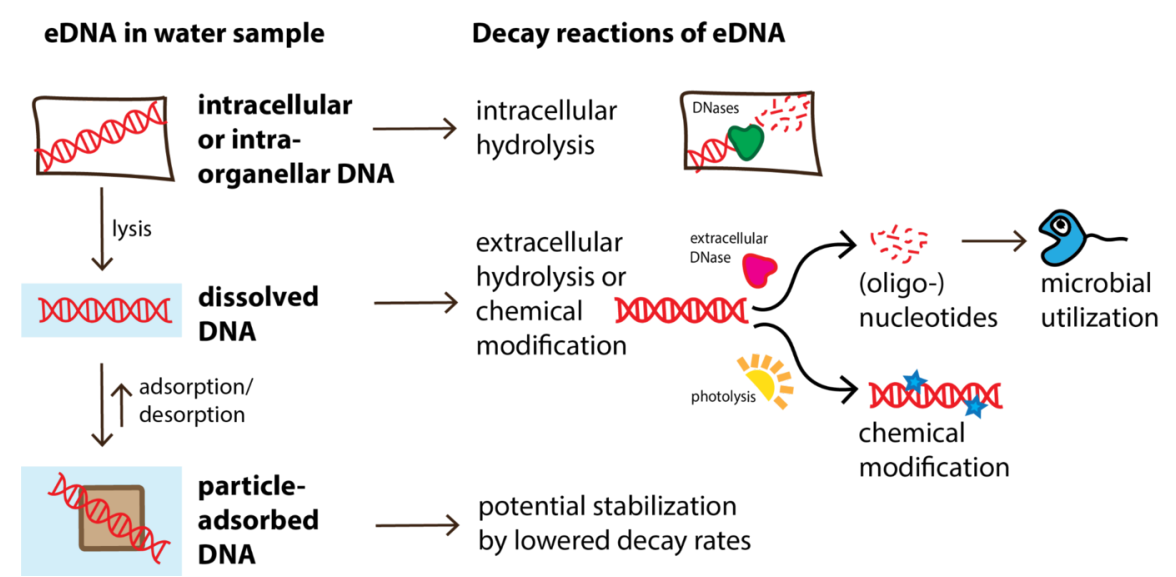

Figure 1: Summary of eDNA states, the processes that convert eDNA between states (cell lysis and adsorption/desorption), and the chemical reactions (intra- and extracellular breakdown, microbial utilization, or stabilization) that degrade or alter eDNA in different states making it inaccessible to capture and detection.

The simplest form in which extra-organismal eDNA is present is a purely dissolved state. DNA is a highly water soluble polyelectrolyte due to the negatively charged phosphodiester groups in the DNA backbone. However, dissolved DNA interacts with and may adsorb to the surfaces of mineral and organic particles and colloids suspended in the water. Particle-adsorbed DNA is therefore a second state. Existing literature on DNA adsorption (e.g., ${ }^{17-24}$ ) suggests that DNA-particle interactions are mainly controlled by electrostatics (which may either be attractive or repulsive for positively and negatively charged particle surfaces, respectively) as well as inner-sphere complex formation on some mineral surfaces ${ }^{25-30}$. The bases connected to deoxyribose (i.e., cytosine, adenine, guanine and thymine) likely only play a small, modulating role on DNA adsorption processes (i.e., these bases are involved in $\mathrm{H}$ bonding between the two complementary DNA strands). DNA can also remain associated with cells that are shed by organisms into the water, either as intracellular DNA (third state) or intraorganellar DNA (fourth state) such as skin cells from mucus or cells from the intestinal tract during defecation. The types of cells shed from any organism and their source remain mostly undescribed, but recent advances using messenger RNA typing may allow us to gain a better understanding of the sources and types of cells that make up eDNA ${ }^{29}$, for instance, intraorganellar DNA may be present in mitochondria and chloroplasts. In fact, many extra-organismal eDNA studies target genes found in organelles due to their high copy number per cell which should increase probability of eDNA detection.

\section{State conversion processes}

\section{Cell and organelle lysis}

The source of extracellular DNA in water samples is cells that cover a broad range of properties and characteristics. In cells without a cell wall (animal cells and protozoa), water chemistry influences cytolysis, whereby osmotic pressures cause cell lysis if not maintained. This converts cellular DNA to dissolved DNA (Figure 1). Conversely, the release of DNA from cells with cell walls (plant cells) results from enzymatic breakdown of the polysaccharides and lignin composing their structure ${ }^{32}$. Thus, the activity of extracellular microbial enzymes is likely the rate-determining step in plant cell lysis. The activity itself increases with increasing enzyme concentration and is sensitive to both temperature and ultraviolet (UV) light exposure ${ }^{33}$. Inside eukaryotic cells are cytoplasmic organelles that contain mitochondrial and chloroplast DNA and consist of a double lipid bilayer membrane and like animal cells, undergo similar lysis processes.

\section{Adsorption-desorption}

The backbone of DNA contains negatively charged phosphodiester groups which play a key role in DNA 
adsorption to mineral and organic particle surfaces. At circumneutral pH, DNA is electrostatically attracted to positively charged mineral surfaces, such as those of iron (oxyhydr-)oxides and aluminium (hydr-)oxides, resulting in strong adsorption. Conversely, DNA is electrostatically repelled from negatively charged surfaces, including silicon dioxide or the basal planes of some clay minerals. Therefore, the importance of adsorbed DNA in a water sample likely increases with increasing suspended amounts of positively charged minerals. Electrostatic DNA-sorbent interactions can be modulated by solution $\mathrm{pH}$ for sorbents that carry a variable charge: increasing $\mathrm{pH}$ decreases the positive charges (and increases the negative charges), thereby weakening electrostatic attraction. Thus, increasing solution $\mathrm{pH}$ is expected to lower DNA adsorption and can facilitate DNA desorption from variably charged surfaces.

DNA-sorbent electrostatic interactions are also modulated by solution ionic strength and composition. Increases in solution ionic strength attenuate both DNA electrostatic attraction to and repulsion from positively and negatively charged surfaces, respectively. At very high ionic strength, electrostatic repulsion from negatively charged surfaces may be attenuated to an extent that close-contact DNA-surface attractive interactions (see below) result in DNA adsorption. The presence of divalent cations in solution may lead to increased adsorption to negatively charged sorbents via 'cation bridging' between the like-charged DNA and the sorbent ${ }^{34-37}$. Therefore, information on the solution ionic strength and concentrations of $\mathrm{Ca}^{2+}$ and $\mathrm{Mg}^{2+}$ is important to assess the extent of DNA adsorption. Besides electrostatic interactions, DNA-surface van der Waals interactions and H-bonding may drive adsorption. However, these energetic contributions are expected to be small in comparison to electrostatic interactions.

All of the aforementioned interactions result in 'physisorption' - the interaction of DNA with the sorbent surface without forming covalent bonds. However, DNA may additionally bind to some surfaces through 'chemisorption', which involves the formation of covalent bonds between the phosphodiester group of the DNA and hydroxyl groups on the mineral surfaces. The resulting 'inner sphere' complexes are very stable and may result in both DNA adsorption to mineral surfaces even at high $\mathrm{pH}$ (despite net negative surface charges on the minerals) as well as prevent DNA desorption from mineral surfaces even if changes in solution conditions result in DNA-sorbent electrostatic repulsion. DNA may thus be irreversibly adsorbed, which is clearly relevant for eDNA decay and detection.

Finally, co-solutes may compete with DNA for adsorption sites on particle surfaces and thereby suppress DNA adsorption. For instance, both dissolved organic matter (DOM) and phosphate are expected to adsorb to some mineral surfaces and may thus increase the fraction of eDNA present in the dissolved state ${ }^{24}$.

\section{Expected and observed decay processes of eDNA}

\section{Expected decay processes}

Chemical reactions of DNA may alter its size and modify its chemical structure, both of which determine its detectability in aquatic samples (Box 1). Chemical reactions include photochemical oxidation, abiotic hydrolysis, and enzymatically mediated hydrolysis (which we refer to as biological degradation since these enzymes are produced by living organisms). Both enzymatic and abiotic reactions cause hydrolytic cleavage of ester bonds in the backbone of DNA and result in the conversion of a longer DNA molecule into shorter molecules. Physical shearing of DNA molecules is also a potential mechanism, but these forces are unlikely in natural aquatic systems (Box 1). The importance of these reactions for using eDNA to infer species presence is that eventually these short molecules can no longer be detected using methods such as PCR. It is assumed that hydrolysis of eDNA can occur both intracellularly and extracellularly (Figure 1), thus affecting multiple eDNA states. Abiotic hydrolysis or photochemical oxidation are likely easier to predict (based on readily measurable chemical parameters such as solution $\mathrm{pH}$ and UV light irradiance) than enzymatic hydrolysis which requires more detailed information concerning type, abundance and activity of the enzymes, as well as the population dynamics of the microorganisms secreting these enzymes. Further, microbial activities (e.g., demand for phosphorus) are expected to be sample and time-specific and may require assessment when a water sample is collected ${ }^{7}$. Adsorption of nucleic acids to particle surfaces has been shown to stabilize these molecules by protecting it from hydrolytic enzymes in water ${ }^{38-41}$. Likewise, there is evidence that particle 
adsorbed DNA is protected from photochemical degradation ${ }^{42}$. Thus, once DNA is bound to surfaces of minerals, it is expected to be stabilized from degradation.

Box 1: Short overview of DNA decay by chemical reactions. For more details, see extensive reviews by ${ }^{3,14,15}$.

\section{Hydrolysis reactions}

DNA decay by hydrolysis can occur abiotically and be enzymatically mediated and is affected by environmental factors (e.g., water $\mathrm{pH}$, temperature, and ionic strength). DNA strands break through enzymatic hydrolysis by so-called DNases. Such DNA enzymatic hydrolysis can occur at high rates and become the main driver of DNA decay as opposed to purely abiotic hydrolysis ${ }^{3,15}$. Determining how environmental parameters change enzymatic hydrolysis rates is complicated by the fact that each species' enzymes potentially exhibit optimal kinetics for different possible combinations of environmental parameters because of a species' evolutionary history of adaptation ${ }^{43}$.

Abiotic hydrolysis reactions, such as depurination (loss of purine base) and deamination of cytosine (elimination of ammonia), followed by strand break cause DNA decay. Chemical depurination rates decrease with decreasing temperature, $\mathrm{pH}$, and ionic strength. Deamination reactions are very slow at temperatures present for most of earth's surface waters (excluding hydrothermal vents) and are therefore unlikely to be an important driver of DNA decay on short time scales of days to weeks ${ }^{44}$. In fact, most estimates of abiotically driven hydrolysis (depurination and deamination) of DNA have half-lives between 70 and 31,000,000 years, but these can be modulated by extreme environmental conditions ${ }^{3}$.

\section{Oxidation reactions}

Radicals generated from UV-A/B light can lead to breaks in single-stranded DNA by forming hydroxyguanine and hydantoions from pyrimidines. This reaction is $\mathrm{pH}$ sensitive. UV light may also cause the formation of pyrimidine dimers in DNA. In addition, UV radiation has many indirect effects through the generation of free radicals, therefore the timescale upon which this mechanism acts to degrade DNA is hard to conclude.

\section{Physical sheering}

Alternative cycles of freezing/thawing have previously been shown to lead to progressive DNA degradation in controlled conditions ${ }^{43}$ (due to the formation of solid ice crystals). Additionally, DNA can be degraded through acoustic sonication or by hydrodynamic shearing in laboratory conditions, e.g. library preparation for sequencing ${ }^{45}$. However, the latter two processes are least likely to occur in natural environments.

\section{Chemical modification}

During interstrand cross-linking, two strands of the DNA molecule become covalently linked preventing full separation of DNA strands using heat. This can be facilitated by UV-A light and the presence of intercalating agents. Interstrand cross-linking makes DNA inaccessible to PCR detection, but this is not degradation per $s e$. We mention this reaction because at this time we cannot differentiate non-detection resulting from true degradation versus interstrand cross-linking using PCR.

\section{Observed decay processes}

In aquatic systems, the reactions expected to lead to DNA decay are likely further influenced by the state that eDNA assumes ${ }^{8}$. We conducted a literature search to evaluate what is known about eDNA decay processes based on temperature, $\mathrm{pH}$ and microbial activity. We collected data from previous literature reviews ${ }^{46,47}$ and supplemented this with published studies that followed (see Table S1 and Figures S1-S2). Values for eDNA half-life in hours were directly extracted or calculated from the reported first order decay rate constant. Data from marine and freshwater organisms, namely fish, crustaceans, amphibians, and insects were included in our analysis, but see Figure 2B. Based on this literature review, exponential decay functions are increasingly fit to experimental DNA decay data showing that, independent of source organism, eDNA decay exhibits a pattern of first-order kinetics. Yet, some studies also demonstrate that a second-order (or biphasic) decay 
rate constant better describes the observed eDNA data ${ }^{48,49}$. As suggested by ${ }^{8}$, the need to fit a biphasic decay rate constant to observed experimental data may indicate that different rates may be associated with different eDNA states. However, because PCR detection of DNA cannot differentiate between states, the first order decay rate constant is likely an integrated estimate for eDNA decay across multiple states contributing to detection. The integrated estimate may be good if the question is "Was this species ever present in this ecosystem?" but integrating across states with unknown persistence times in the environment can decrease the accuracy of this inference if a finer temporal resolution of species presence is sought.

Studies to date (see Table S1) include both semi-natural or experimental aquatic systems but have thus far measured animal eDNA (especially fish), leaving much to be explored for what happens to plant and other animal eDNA in the water column. Broadly, observations are that animal eDNA rate constants of decay increase with increasing temperatures $\left(>20^{\circ} \mathrm{C}\right)$ but decrease with more basic $(\mathrm{pH}>5.0)$ or alkaline solutions $(\mathrm{pH}>9.0)$ (Figure 2a, b). Enzyme kinetics depend on the same parameters that affect abiotic DNA decay, for example, temperature, $\mathrm{pH}$, UV-B light irradiation, and co-factors such as metal ions that either enhance or inhibit enzymatic activity ${ }^{50}$. Thus, we would expect these environmental parameters to be highly correlated with eDNA decay rates whether or not enzymes are involved. A single study has co-measured eDNA in different states (cell vs. dissolved DNA) and found differences in the decay rates between states for pond water but not salt water ${ }^{45}$. This suggests that water chemistry in different habitats may play a role in degradation of different states.

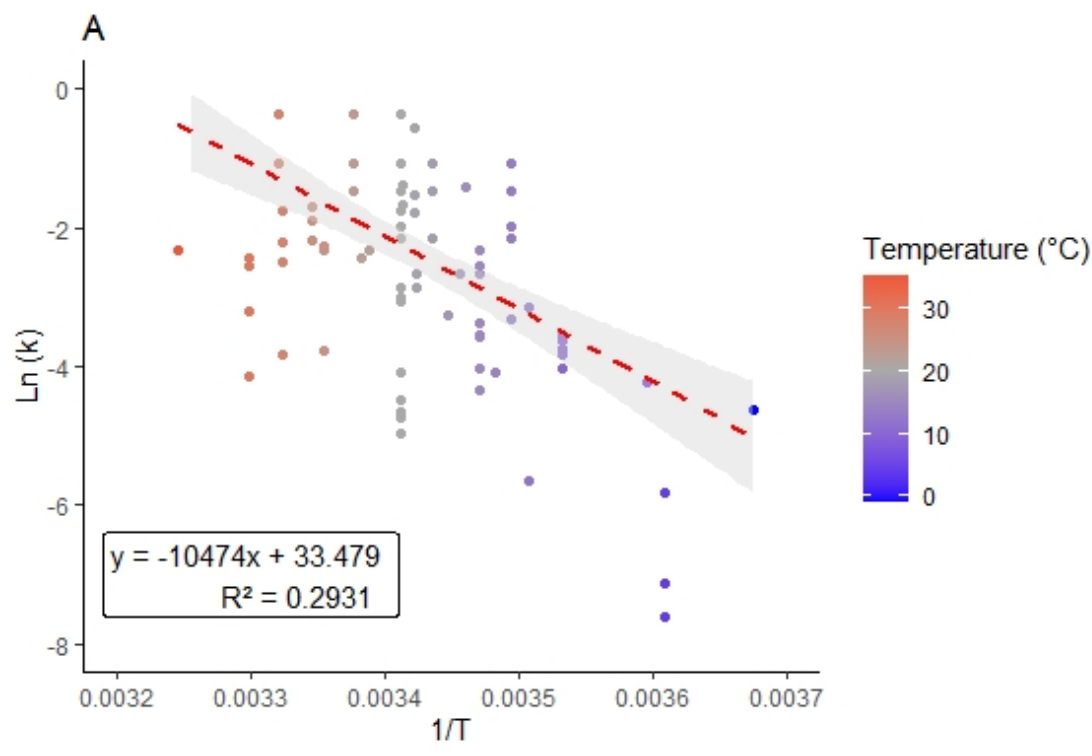




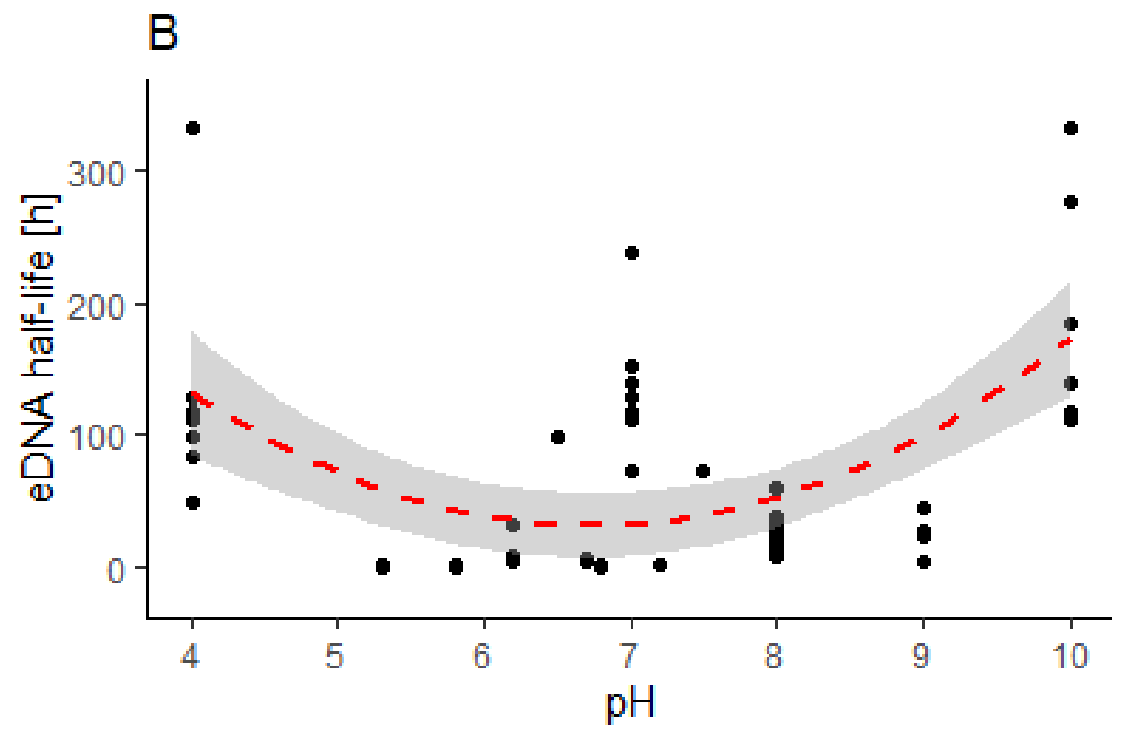

Figure 2: (a) Fish eDNA decay in relation to temperature. Data for marine and freshwater fish were included. The natural logarithm of the decay constant $\mathrm{k}$ is plotted against the reciprocal values of the temperature expressed in Kelvin $[1 / \mathrm{T}]$, analogous to the temperature dependence of reaction rates presented in the Arrhenius equation. (b) eDNA data from amphibians, fish and crustaceans in relation to water $\mathrm{pH}$. eDNA half-life (in hours) is plotted against $\mathrm{pH}$ of water where the organisms were present. Data were extracted from ${ }^{46,47,51}$ and visualized using the $\mathrm{R}$ package ggplot2 $\mathrm{v} 3.3 .3$.

Lastly, microbial abundance and activity are expected to play an important role in animal and plant eDNA decay in water ( ${ }^{6}$ and references therein). While studies have been performed on soil and sediments ${ }^{52-55}$, no systematic experiment has been conducted to determine the relative importance of abiotic versus biotic DNA degradation in water. Several studies have suggested higher microbial activity contributes to the faster DNA degradation observed at higher temperatures ${ }^{43,46,56,57}$, which appears to be supported by a mesocosm experiment that examined the influence of microbial activity on fish eDNA degradation. However, the experiment did not control bacterial abundance independently of temperature or time ${ }^{58}$. Another study examining bacterial abundance in relation to eDNA used radio-labelling as opposed to PCR amplification of natural seawater samples ${ }^{7}$, thus results are based on total eDNA as opposed to animal and/or plant eDNA. Bacteria are known to graze on DNA for nutrients in aquatic ecosystems through extracellular enzymes and ectoenzymes (e.g., nucleases on the surface of their cells that hydrolyse DNA ${ }^{11,15}$ ). Active DNA degrading enzymes have been found in filtered water fractions containing bacteria, cyanobacteria, algae, fungi, and single- and multicellular plankton animals, but some enzyme types (e.g., 5'-nucleotidase) have only been found on the surface of bacteria cells ${ }^{59}$. Another study employed antibiotics to decrease bacterial loads and found that antibiotics decreased eDNA decay rates to smaller values than measured under higher bacterial loads in untreated samples ${ }^{45}$, suggesting that microbial decay is the main driver. However in both of these studies, there was no control without bacteria to determine the relative importance of abiotic reactions. If enzymes secreted by cells are the main driver of hydrolysis of DNA, the subsequent nutrient utilization (N and $\mathrm{P}$ ) by microbial cells is a plausible mechanism for the shorter decay rates (hours to days) observed for animal eDNA in natural water compared to abiotic reactions which occur over much longer timescales (Box $1)^{7}$. This would lead to environment-specific rates of eDNA decay requiring an understanding of both $\mathrm{N}$ and P limitation, and the parameters that control eDNA state (discussed in the "State conversion processes" section).

Identifying information needed to understand eDNA states, decay and implications for species detection 
We have discussed four eDNA states (dissolved, particle-absorbed, intracellular, inter-organellar) from eukaryotic organisms that are likely to be present in aquatic environments. Processes responsible for conversion between states and eDNA decay are detailed and well understood. Studies of eDNA decay in natural and artificial aquatic systems to date provide evidence that environmental parameters affect DNA decay rates in water $^{3}$. We have made the case that chemical reactions that cause eDNA decay are likely to be state-specific and decay rate constants are influenced by the physical and chemical properties of aquatic environments. Thus, the next step is to form a greater understanding of what states are present for analysis in natural systems.

With this in mind, a meta-analysis of published eDNA studies targeting single species was performed to assess whether we could ascertain what eDNA states are being analysed overall, and whether the detection of the species' DNA from a specific environmental context could inform which eDNA state was present. We note that this literature review may potentially be biased by methodologies that resulted in a positive eDNA detection from water samples (as non-detections are less likely to be published). Details of the search and analysis are presented in the Supporting Information. Because of the chemical properties of eDNA states, we know that molecular purification protocols can select and potentially isolate different states from a water sample (e.g. $\left.{ }^{60}\right)$. Thus, we focused our literature review on methods used to isolate eDNA from a water sample and infer what states were likely analysed. We also recorded what environmental parameters were co-measured at the time of sampling.

Our literature review of 74 peer-reviewed articles showed that most eDNA studies are broadly employing the same molecular methods for DNA capture (i.e., filtration) and extraction (i.e., enzyme and chemical) albeit in different combinations (Figure 3).

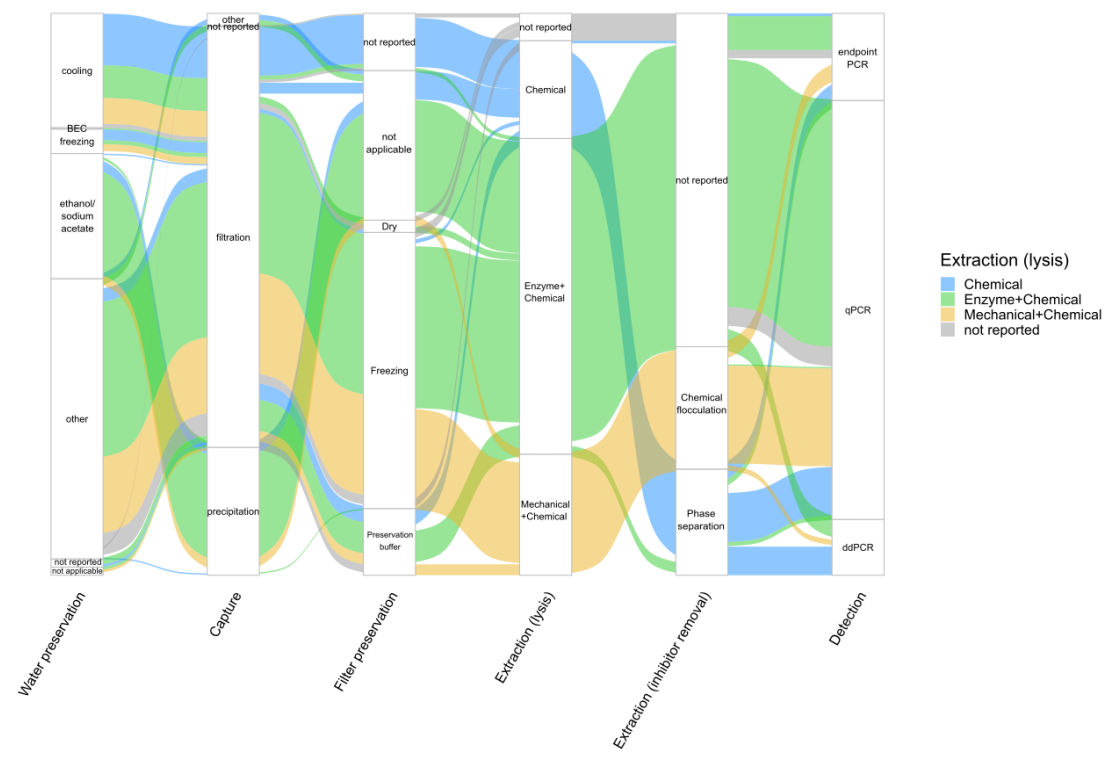

Figure 3: Sankey diagram summarising water preservation, capture, filter preservation, extraction (lysis and inhibitor removal), and detection methods used by studies included in our literature review.

Most assays $(n=100)$ targeted fish $(49.0 \%)$, followed by crustaceans (17.0\%) (Figure S3a). The majority of assays $(n=123)$ were used for quantification $(39.8 \%)$ or detection $(35.8 \%)$ (Figure S3b), and used in the Palearctic (45.3\%) or Nearctic $(40.7 \%)$ (Figure S3d). Assays were usually deployed in natural environments $(n=84)$, specifically lentic $(20.7 \%)$ or lotic $(26.5 \%)$ freshwater systems (Figure. S3c). Where assays were used in experimental systems (classed as 'other' for environment), the volume of these artificial water systems 
ranged from $900 \mathrm{ml}$ to $336,000 \mathrm{~L}$ (median $=20 \mathrm{~L}$ ). Sample sizes (i.e., number of sampling sites) ranged from 1 to 197 (median $=4$ ), with between 1 and 120 biological replicates (median $=5$ ) taken, and between $15 \mathrm{ml}$ and $6 \mathrm{~L}$ of water $($ median $=500 \mathrm{ml})$ collected per biological replicate.

The broad workflows used by assays included in our literature review are summarised in Figure 3. Most assays used cooling $(n=25)$ after 'other' ( $n=58$, typically centrifugation or resin beads) for water sample preservation, followed by filtration $(n=126$; Figures 3, S4) for eDNA capture. Ethanol/sodium acetate $(n$ $=5)$ for water sample preservation followed by precipitation $(n=31)$ for eDNA capture was less popular but constituted a second major analytical workflow (Figures 3, S4). Of those assays using filtration, glass fibre filter membranes ( $0.7 \mu \mathrm{m}$ pore size) were most commonly used, followed by polycarbonate track-etched, cellulose nitrate, nylon and 'other' membrane types, including cellulose acetate and polyethersulfone (Figure S5). Filters were typically frozen at -20 for preservation of DNA in the retentate (Figure 3), but storage times were often not reported. A full breakdown of precipitation and filtration methods can be found in Supporting Information (Figures S6, S7).

The vast majority of assays $(n=125)$ used commercial extraction kits $(82.0 \%)$ as opposed to unbranded protocols (18.0\%) (Figure S8), with the Qiagen DNeasy Blood and Tissue Kit being the most commonly used $(47.76 \% ; n=110)$ (Figure S9). Mechanical disruption with chemicals and chemicals only were secondary to an enzyme with chemicals for cell lysis (Figure 3). Commercial kits typically employed an enzyme with temperature to induce cell lysis and lacked an inhibitor removal step, yet post-extraction inhibitor removal was uncommon (Figure S10). Where post-extraction inhibitor removal was performed, this was either done by phase separation or chemical flocculation (Figure 3) using methods such as the Zymo One Step PCR Inhibitor Removal Kit, the Promega Wizard Genomic DNA Purification Kit, chloroform or dilution.

Most assays $(n=136)$ targeted mitochondrial genes using quantitative PCR (69.9\%) (Figures 3, S11). Typically, three technical replicates were performed in $20 \mu \mathrm{l}$ reactions using $2 \mu \mathrm{l}$ of template DNA. The majority of assays (80.0\%) did not use an internal positive control to test for inhibition and did not determine the Limit of Detection (54.4\%), Limit of Quantification (71.0\%) or effects of the environmental matrix (78.0\%) (Figure S12). Most assays used commercial master mixes (Figure S13), such as Applied Biosystems TaqMan Environmental Master Mix 2.0 and TaqMan Gene Expression Master Mix (Figure S14), as opposed to custom master mixes. Where custom master mixes were used, $\mathrm{MgCl}_{2}$ concentration ranged from 1.5 to 2.5 (median $=2$ ) and dNTP concentration ranged from 0.05 to 0.25 (median $=0.20)$. Promega $5 x$ Colorless GoTaq Flexi Reaction Buffer and Promega GoTaq Flexi DNA Polymerase were the most commonly used buffer type and enzyme type respectively. Enhancers were not often added to PCR reactions, but Bovine Serum Albumin (BSA) was most common where enhancers were used (21.3\%) (Figure S15).

Crucially, most assays $(n=145)$ did not measure, record or report environmental parameters that are expected to affect the distribution of DNA among states and determine stability of DNA (Figure S16). Parameters that were recorded and reported included temperature (50.3\%), $\mathrm{pH}(22.0 \%)$, UV exposure (9.0\%), season $(68.0 \%)$, canopy cover $(3.0 \%)$, conductivity/salinity $(22.0 \%)$, geology of catchment $(12.0 \%)$ and dissolved oxygen (15.0\%). One third of papers would require the authors to be contacted to clarify their analytical workflow or ascertain if they collected environmental data but did not report it (Figure S17).

Taken all together, our meta-analysis suggests that most single-species studies employ methods that analyse a similar and potentially restricted state of eDNA. The majority of studies use filtration at pore sizes through which most dissolved eDNA may pass if clogging does not occur. After filtration, the eDNA on the filter is isolated with similar lysis methods and purification buffers provided with commercial extraction kits that fundamentally employ similar chemistry (see Table S2). Most of these commercial kits likely do not promote particle bound DNA to desorb. To be certain, the constituents of the buffers would need to be determined which was not feasible since most of these are trade secrets. If these commercial kit buffers do not have competitive binders and do not reach a $\mathrm{pH}$ high enough to promote desorption, it is likely that DNA adsorbed onto particles was not isolated. If these assumptions are true (i.e. dissolved DNA flows through filters and extraction kit buffers do not promote desportion), then eDNA detections from the studies reviewed here may originate from only inter-cellular or organellar DNA. However, extensive research comparing whether 
specific molecular methods co-purify eDNA states would be needed to verify this claim.

\section{How do we create analytical controls for state?}

The importance of appropriate analytical controls in eDNA research is well established (e.g., $\left.{ }^{13,61}\right)$. These include field and laboratory controls that are designed to assess contamination (negative controls) ${ }^{62}$, analytical precision (biological and technical replicates), and sensitivity (positive controls). However, these controls do not account for eDNA being present in different states nor do these controls allow assessment of whether eDNA in each state(s) is accurately quantified. Moreover, incomplete recovery of analytical controls typically leads to the conclusion that PCR inhibition is involved. While this clearly is a possibility, we propose that results could also be confounded because current protocols may not completely extract DNA from all four states if present in the sample. Therefore, additional analytical controls are needed to disambiguate the cause of observed signal attenuation (e.g., PCR inhibition versus inefficient extraction across states).

There are various analytical controls employed in the eDNA literature, but these are inconsistently applied. Some researchers (e.g., ${ }^{63}$ ) advocate multiplexing an assay for a given target species together with an assay designed to detect a co-occurring species presumed to be ubiquitous in the environment, such as algae (e.g., using a generalized plant chloroplast DNA assay), to demonstrate that the PCR reaction was not inhibited. Yet, because the state (Figure 1) and concentration of any species' eDNA is unknown, it cannot be used to assess relative rates of PCR inhibition and/or inefficient eDNA recovery. To address this issue, internal standards of known DNA concentration and state could be applied at various stages in the workflow (Figure 4). Synthetic DNA has been used as an internal positive control to quantitate the relative degree of PCR inhibition, but this does not account for inefficient extraction of different eDNA states. Applying a "spike in" control prior to the extraction/precipitation step could result in some sorption of the control DNA, but again the attenuation of the PCR signal could not be used to discriminate between inhibition and inefficient recovery.

Developing analytical controls to assess whether eDNA is bound to cellular debris, adsorbed to particles or dissolved in solution remains a challenge. Size fractionation can be achieved by filtering a sample through multiple filters of progressively smaller pore size and subsequently extracting eDNA from each individual filter and the filtrate. Assuming any DNA that passed through the filters into the filtrate represents dissolved eDNA and potentially even particles, it is possible to quantify this pool. However, eDNA recovered from the filters cannot be separated into cellular bound vs. particle bound DNA without utilizing extraction protocols optimized to recover only particle bound or cellular debris bound eDNA. Protocols for separating soluble DNA (i.e., extracellular and bound to particles) from insoluble DNA (i.e., still inside the cell) have been developed ${ }^{60}$. Their parallel application to known mixtures of cellular bound, particle bound and dissolved eDNA could prove illuminating by separating out the different states and analysing them separately for detection of a target species or community. However, quantifying the eDNA in each category before assembling the mixtures would be non-trivial and even then, the approach could not easily assess the dynamic conversion of DNA between states that may occur during the extraction. These issues notwithstanding, the combined use of cellular material, plasmids (e.g. as surrogates for organelles), synthetic DNA and varied adsorbent materials, together with size fractionation and multiple extraction techniques as applied across a gradient of environmental conditions could yield novel insights concerning extraction efficiency among eDNA states and the dynamic conversion processes between them when selectively applied to each sample processing step (Figure 4). 


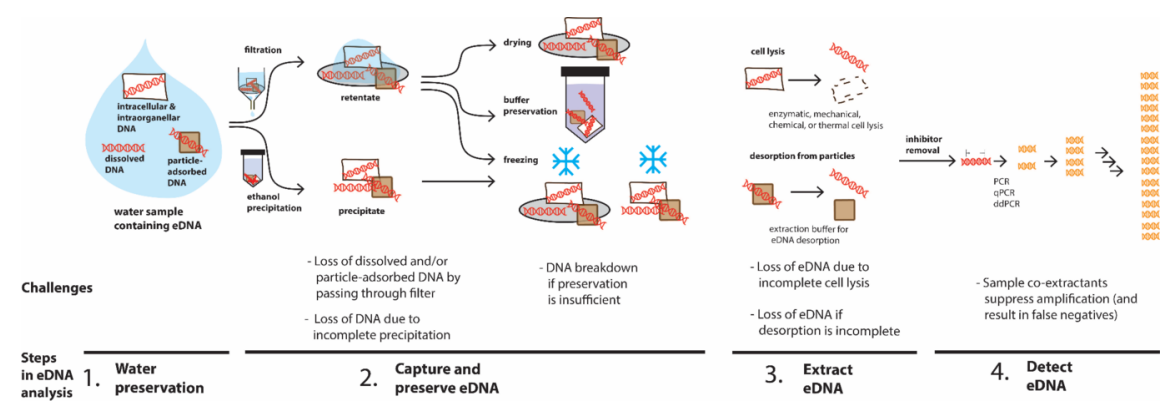

Figure 4: Sample processing steps used for water preservation, eDNA capture and preservation, eDNA extraction and eDNA detection. Each step can be done in several ways and each can likely have a challenge associated with loss of a particular eDNA state.

\section{Recommendations for analytical procedures and future experiments}

A growing body of literature demonstrates that eDNA-based detection is a powerful, sensitive and noninvasive method of biodiversity detection, yet the extent to which existing methods may be susceptible to inefficiencies remains to be systematically investigated. It is evident that at least four states of eDNA exist and not all of them may be captured by the various combinations of methods (Figure 3) used to isolate DNA from water.

To maximize detection rates, methods that capture and isolate DNA from all states should ideally be utilized, such as water filtration using different pore sizes (i.e., to capture particle bound or cellular DNA and avoid clogging the filter) followed by precipitation of the filtrate (i.e., to capture dissolved DNA). Specifically, adsorption effects should be considered when capturing and extracting eDNA from turbid waters, or in the presence of highly concentrated suspended solids as on a filter. A side effect of DNA extraction is the release of intracellular DNA during cell lysis which could encounter positively charged mineral surfaces that were co-captured during filtration, resulting in the newly released DNA becoming particle bound during extraction and subsequently reduced DNA yield. In such cases, extraction buffers that effectively extract DNA from mineral surfaces will need to have the corresponding compositions to favour desorption and prevent adsorption of DNA liberated from cells. In particular, these extraction buffers should: (i) have a sufficiently high (i.e., alkaline, $\mathrm{pH} \mathrm{9-10)} \mathrm{pH}$ to result in DNA-sorbent electrostatic repulsion, but not too high to facilitate base-catalysed DNA backbone hydrolysis, (ii) contain competing co-adsorbates such as phosphate, pentaphosphate, or possibly a DNA molecule that does not contain the targeted sequence of the analyte DNA, and (iii) contain complexing agents for divalent cations to minimize the possibility of cation bridging of DNA to negatively charged sorbent surfaces. Notably, extraction protocols developed for soil and sediment may be more efficient for the extraction of eDNA from water with a high concentration of particles whose surfaces can adsorb DNA, particularly if these particles are concentrated with eDNA during filtration ${ }^{64}$. A systematic DNA extraction assessment using artificial control samples with known concentrations of freely dissolved, particle-adsorbed and intracellular DNA is needed to determine which states are most efficiently captured by common extraction protocols. This would aid optimization of the extraction protocol and account for the different eDNA states while maximizing their extraction efficiency ${ }^{3,65}$.

Where possible, we recommend that eDNA practitioners employ methods to capture multiple states of eDNA. All samples should then be combined for analysis or analysed independently if eDNA states are likely to influence the research or management questions under investigation, (e.g., inferences of where and when a species was present ${ }^{3}$ ). If it is impossible to extract all eDNA states at every study site, we recommend that eDNA practitioners resample sites that are suspected false negatives should their chosen methods of eDNA capture and extraction (most likely filtration and a commercial DNA extraction kit) fail to produce eDNA detections. However, a caveat to the above is that if different states have different decay rates (e.g., particle bound DNA might persist longer than dissolved DNA), then the time and space inference as to when a species was present in the sampled environment becomes less clear. Thus, for accurate inferences of time 
and space, not just detection, more research is required to determine concentration dynamics for all eDNA states present in different ecosystems ${ }^{3}$.

\section{Conclusions}

Environmental DNA exists in a mixture of different states (e.g., dissolved, particle-adsorbed, intra-cellular and organellar) and each state is expected to have a specific decay rate that depends on the complex interplay of varied environmental parameters. Our effort to provide a comprehensive review of the parameters affecting state-dependent eDNA decay rates and the mechanisms involved have yielded some important insights. Notably, water chemistry and suspended mineral particles likely affect conversion of eDNA among states and persistence of eDNA states in the water column. However, the eDNA literature contains inconsistently reported metadata and sometimes conflicting results, thus further study of how environmental parameters affect eDNA state conversion and decay in aquatic environments is needed. Improving our understanding of these issues will require a concerted effort by the scientific community to collect more comprehensive and consistent metadata on environmental conditions at the time of sampling. It will also require the implementation of analytic eDNA controls during sample collection, preservation, extraction and analysis to better understand eDNA state conversion and decay in aquatic environments. This represents a crucial research agenda for the field, given the shift toward using eDNA as a tool to support management decisions pertaining to invasive alien species, species at risk and other valued ecosystem component species.

\section{Acknowledgements}

We thank Graham Sellers and Mya Breitbart for their important comments and suggestions on our manuscript. K.D. and H.K. have been supported by the European Research Council (ERC) under the European Union's Horizon 2020 research and innovation programme (Grant agreement No. 852621).

\section{Conflict of Interest:}

KD is the co-founder of SimplexDNA and LRH is a Product Manager for NatureMetrics Ltd., which are for profit companies providing DNA-based solutions for biodiversity monitoring.

\section{Hosted file}

Supporting_Information.docx available at https://authorea.com/users/444195/articles/544374the-multiple-states-of-environmental-dna-and-what-is-known-about-their-persistence-inaquatic-environments

\section{Hosted file}

TableS2_DNA_extraction_methods.xlsx available at https://authorea.com/users/444195/ articles/544374-the-multiple-states-of-environmental-dna-and-what-is-known-about-theirpersistence-in-aquatic-environments

\section{References}

(1) Rees, H. C.; Maddison, B. C.; Middleditch, D. J.; Patmore, J. R. M.; Gough, K. C. REVIEW: The Detection of Aquatic Animal Species Using Environmental DNA - a Review of EDNA as a Survey Tool in Ecology. J. Appl. Ecol.2014, 51 (5), 1450-1459. https://doi.org/10.1111/1365-2664.12306.

(2) Deiner, K.; Fronhofer, E. A.; Meachler, E.; Walser, J.-C.; Altermatt, F. Environmental DNA Reveals That Rivers Are Conveyer Belts of Biodiversity Information. 2015.

(3) Harrison, J. B.; Sunday, J. M.; Rogers, S. M. Predicting the Fate of EDNA in the Environment and Implications for Studying Biodiversity. Proc. R. Soc. B Biol. Sci. 2019, 9.

(4) Jerde, C. L.; Chadderton, W. L.; Mahon, A. R.; Renshaw, M. A.; Corush, J.; Budny, M. L.; Mysorekar, S.; Lodge, D. M. Detection of Asian Carp DNA as Part of a Great Lakes Basin-Wide Surveillance Program. Can. J. Fish. Aquat. Sci. 2013, 70 (4), 522-526. https://doi.org/10.1139/cjfas-2012-0478. 
(5) Biggs, J.; Ewald, N.; Valentini, A.; Gaboriaud, C.; Dejean, T.; Griffiths, R. A.; Foster, J.; Wilkinson, J. W.; Arnell, A.; Brotherton, P.; Williams, P.; Dunn, F. Using EDNA to Develop a National Citizen ScienceBased Monitoring Programme for the Great Crested Newt (Triturus Cristatus).Biol. Conserv. 2015, 183, 19-28. https://doi.org/10.1016/j.biocon.2014.11.029.

(6) Barnes, M. A.; Turner, C. R.; Jerde, C. L.; Renshaw, M. A.; Chadderton, W. L.; Lodge, D. M. Environmental Conditions Influence EDNA Persistence in Aquatic Systems. Environ. Sci. Technol. 2014, 48 (3), 1819-1827. https://doi.org/10.1021/es404734p.

(7) Salter, I. Seasonal Variability in the Persistence of Dissolved Environmental DNA (EDNA) in a Marine System: The Role of Microbial Nutrient Limitation.PLOS ONE 2018, 13 (2), e0192409. https://doi.org/10.1371/journal.pone.0192409.

(8) Jo, T.; Minamoto, T. Complex Interactions between Environmental DNA (EDNA) State and Water Chemistries on EDNA Persistence Suggested by Meta-analyses. Mol. Ecol. Resour. 2021, 21 (5), 14901503. https://doi.org/10.1111/1755-0998.13354.

(9) Rodriguez-Ezpeleta, N.; Morissette, O.; Bean, C. W.; Manu, S.; Banerjee, P.; Lacoursière-Roussel, A.; Beng, K. C.; Alter, S. E.; Roger, F.; Holman, L. E.; Stewart, K. A.; Monaghan, M. T.; Mauvisseau, Q.; Mirimin, L.; Wangensteen, O. S.; Antognazza, C. M.; Helyar, S. J.; Boer, H.; Monchamp, M.; Nijland, R.; Abbott, C. L.; Doi, H.; Barnes, M. A.; Leray, M.; Hablutzel, P. I.; Deiner, K. Trade-offs between Reducing Complex Terminology and Producing Accurate Interpretations from Environmental DNA: Comment on "Environmental DNA: What's behind the Term?" By Pawlowski et al., (2020). Mol. Ecol. 2021, mec.15942. https://doi.org/10.1111/mec.15942.

(10) Jo, T.; Takao, K.; Minamoto, T. Linking the State of Environmental DNA to Its Application for Biomonitoring and Stock Assessment: Targeting Mitochondrial/Nuclear Genes, and Different DNA Fragment Lengths and Particle Sizes. Environ. DNA 2021, edn3.253. https://doi.org/10.1002/edn3.253.

(11) Siuda, W.; Chrost, R. Concentration and Susceptibility of Dissolved DNA for Enzyme Degradation in Lake Water-Some Methodological Remarks. Aquat. Microb. Ecol. 2000, 21, 195-201. https://doi.org/10.3354/ame021195.

(12) Deiner, K.; Bik, H. M.; Machler, E.; Seymour, M.; Lacoursiere-Roussel, A.; Altermatt, F.; Creer, S.; Bista, I.; Lodge, D. M.; de Vere, N.; Pfrender, M. E.; Bernatchez, L. Environmental DNA Metabarcoding: Transforming How We Survey Animal and Plant Communities. Mol. Ecol. 2017. https://doi.org/10.1111/mec.14350.

(13) Goldberg, C. S.; Turner, C. R.; Deiner, K.; Klymus, K. E.; Thomsen, P. F.; Murphy, M. A.; Spear, S. F.; McKee, A.; Oyler-McCance, S. J.; Cornman, R. S.; Laramie, M. B.; Mahon, A. R.; Lance, R. F.; Pilliod, D. S.; Strickler, K. M.; Waits, L. P.; Fremier, A. K.; Takahara, T.; Herder, J. E.; Taberlet, P. Critical Considerations for the Application of Environmental DNA Methods to Detect Aquatic Species. Methods Ecol. Evol. 2016,7 (11), 1299-1307. https://doi.org/10.1111/2041-210X.12595.

(14) Gates, K. S. The Chemical Reactions of DNA Damage and Degradation. In Reviews of Reactive Intermediate Chemistry; Platz, M. S., Moss, R. A., Jones, M., Eds.; John Wiley \& Sons, Inc.: Hoboken, NJ, USA, 2007; pp 333-378. https://doi.org/10.1002/9780470120828.ch8.

(15) Torti, A.; Lever, M. A.; Jorgensen, B. B. Origin, Dynamics, and Implications of Extracellular DNA Pools in Marine Sediments. Mar. Genomics2015, 24, 185-196. https://doi.org/10.1016/j.margen.2015.08.007.

(16) Lacoursiere-Roussel, A.; Deiner, K. Environmental DNA Is Not the Tool by Itself. J. Fish Biol. 2021, 98 (2), 383-386. https://doi.org/10.1111/jfb.14177.

(17) Sakai, Y. Improvements in Extraction Methods of High-Molecular-Weight DNA from Soils by Modifying Cell Lysis Conditions and Reducing Adsorption of DNA onto Soil Particles. Microbes Environ. 2021, 36(3), n/a. https://doi.org/10.1264/jsme2.ME21017. 
(18) Vandeventer, P. E.; Lin, J. S.; Zwang, T. J.; Nadim, A.; Johal, M. S.; Niemz, A. Multiphasic DNA Adsorption to Silica Surfaces under Varying Buffer, PH, and Ionic Strength Conditions. J. Phys. Chem. B 2012,116 (19), 5661-5670. https://doi.org/10.1021/jp3017776.

(19) Vandeventer, P. E.; Mejia, J.; Nadim, A.; Johal, M. S.; Niemz, A. DNA Adsorption to and Elution from Silica Surfaces: Influence of Amino Acid Buffers. J. Phys. Chem. B 2013, 117 (37), 10742-10749. https://doi.org/10.1021/jp405753m.

(20) James Cleaves, H.; Crapster-Pregont, E.; Jonsson, C. M.; Jonsson, C. L.; Sverjensky, D. A.; Hazen, R. A. The Adsorption of Short Single-Stranded DNA Oligomers to Mineral Surfaces. Chemosphere 2011, 83 (11), 1560-1567. https://doi.org/10.1016/j.chemosphere.2011.01.023.

(21) Nguyen, T. H.; Elimelech, M. Adsorption of Plasmid DNA to a Natural Organic MatterCoated Silica Surface: Kinetics, Conformation, and Reversibility.Langmuir 2007, 23 (6), 3273-3279. https://doi.org/10.1021/la0622525.

(22) Cai, P.; Huang, Q.; Zhang, X.; Chen, H. Adsorption of DNA on Clay Minerals and Various Colloidal Particles from an Alfisol. Soil Biol. Biochem.2006, 38 (3), 471-476. https://doi.org/10.1016/j.soilbio.2005.05.019.

(23) Nguyen, T. H.; Elimelech, M. Plasmid DNA Adsorption on Silica: Kinetics and Conformational Changes in Monovalent and Divalent Salts.Biomacromolecules 2007, 8 (1), 24-32. https://doi.org/10.1021/bm0603948.

(24) Sodnikar, K.; Parker, K. M.; Stump, S. R.; ThomasArrigo, L. K.; Sander, M. Adsorption of DoubleStranded Ribonucleic Acids (DsRNA) to Iron (Oxyhydr-)Oxide Surfaces: Comparative Analysis of Model DsRNA Molecules and Deoxyribonucleic Acids (DNA). Environ. Sci. Process. Impacts2021, 23 (4), 605620. https://doi.org/10.1039/D1EM00010A.

(25) Omoike, A.; Chorover, J.; Kwon, K. D.; Kubicki, J. D. Adhesion of Bacterial Exopolymers to R-FeOOH: Inner-Sphere Complexation of Phosphodiester Groups. Langmuir 2004, No. 20, 11108-11114.

(26) Omoike, A.; Chorover, J. Spectroscopic Study of Extracellular Polymeric Substances from Bacillus s Ubtilis : Aqueous Chemistry and Adsorption Effects. Biomacromolecules 2004, 5 (4), 1219-1230. https://doi.org/10.1021/bm034461z.

(27) Omoike, A.; Chorover, J. Adsorption to Goethite of Extracellular Polymeric Substances from Bacillus Subtilis. 2006, 12.

(28) Cao, Y.; Wei, X.; Cai, P.; Huang, Q.; Rong, X.; Liang, W. Preferential Adsorption of Extracellular Polymeric Substances from Bacteria on Clay Minerals and Iron Oxide. Colloids Surf. B Biointerfaces 2011,83 (1), 122-127. https://doi.org/10.1016/j.colsurfb.2010.11.018.

(29) Parikh, S. J.; Chorover, J. ATR-FTIR Spectroscopy Reveals Bond Formation During Bacterial Adhesion to Iron Oxide. Langmuir 2006,22 (20), 8492-8500. https://doi.org/10.1021/la061359p.

(30) Parikh, S. J.; Mukome, F. N. D.; Zhang, X. ATR-FTIR Spectroscopic Evidence for Biomolecular Phosphorus and Carboxyl Groups Facilitating Bacterial Adhesion to Iron Oxides. Colloids Surf. B Biointerfaces 2014, 119, 38-46. https://doi.org/10.1016/j.colsurfb.2014.04.022.

(31) Tsuri, K.; Ikeda, S.; Hirohara, T.; Shimada, Y.; Minamoto, T.; Yamanaka, H. Messenger RNA Typing of Environmental RNA (ERNA): A Case Study on Zebrafish Tank Water with Perspectives for the Future Development of ERNA Analysis on Aquatic Vertebrates. Environ. DNA 2021, 3 (1), 14-21. https://doi.org/10.1002/edn3.169.

(32) Agger, J. W.; Isaksen, T.; Varnai, A.; Vidal-Melgosa, S.; Willats, W. G. T.; Ludwig, R.; Horn, S. J.; Eijsink, V. G. H.; Westereng, B. Discovery of LPMO Activity on Hemicelluloses Shows the Importance of 
Oxidative Processes in Plant Cell Wall Degradation. Proc. Natl. Acad. Sci.2014, 111 (17), 6287-6292. https://doi.org/10.1073/pnas.1323629111.

(33) Thomson, B.; Hepburn, C. D.; Lamare, M.; Baltar, F. Temperature and UV Light Affect the Activity of Marine Cell-Free Enzymes. Biogeosciences 2017, 14 (17), 3971-3977. https://doi.org/10.5194/bg-14-39712017.

(34) Minasov, G.; Tereshko, V.; Egli, M. Atomic-Resolution Crystal Structures of B-DNA Reveal Specific Influences of Divalent Metal Ions on Conformation and Packing. J. Mol. Biol. 1999, 291 (1), 83-99. https://doi.org/10.1006/jmbi.1999.2934.

(35) Anastassopoulou, J. Metal-DNA Interactions. J. Mol. Struct. 2003,19 (26), 651-653.

(36) Serra, M. J.; Baird, J. D.; Dale, T.; Fey, B. L.; Retatagos, K.; Westhof, E. Effects of Magnesium Ions on the Stabilization of RNA Oligomers of Defined Structures. RNA 2002, 8 (3), 307-323. https://doi.org/10.1017/S1355838202024226.

(37) Sheng, X.; Qin, C.; Yang, B.; Hu, X.; Liu, C.; Waigi, M. G.; Li, X.; Ling, W. Metal Cation Saturation on Montmorillonites Facilitates the Adsorption of DNA via Cation Bridging. Chemosphere 2019, 235, 670-678. https://doi.org/10.1016/j.chemosphere.2019.06.159.

(38) Mitter, N.; Worrall, E. A.; Robinson, K. E.; Li, P.; Jain, R. G.; Taochy, C.; Fletcher, S. J.; Carroll, B. J.; Lu, G. Q.; Xu, Z. P. Clay Nanosheets for Topical Delivery of RNAi for Sustained Protection against Plant Viruses. Nat. Plants 2017, 3 (2), 16207. https://doi.org/10.1038/nplants.2016.207.

(39) Cai, P.; Huang, Q.-Y.; Zhang, X.-W. Interactions of DNA with Clay Minerals and Soil Colloidal Particles and Protection against Degradation by DNase.Environ. Sci. Technol. 2006, 40 (9), 2971-2976. https://doi.org/10.1021/es0522985.

(40) Parker, K. M.; Barragan Borrero, V.; van Leeuwen, D. M.; Lever, M. A.; Mateescu, B.; Sander, M. Environmental Fate of RNA Interference Pesticides: Adsorption and Degradation of DoubleStranded RNA Molecules in Agricultural Soils.Environ. Sci. Technol. 2019, 53 (6), 3027-3036. https://doi.org/10.1021/acs.est.8b05576.

(41) Stotzky, G. Persistence and Biological Activity in Soil of the Insecticidal Proteins from Bacillus Thuringiensis, Especially from Transgenic Plants.Plant Soil 2005, 266 (1-2), 77-89. https://doi.org/10.1007/s11104-005-5945-6.

(42) Scappini, F.; Casadei, F.; Zamboni, R.; Franchi, M.; Gallori, E.; Monti, S. Protective Effect of Clay Minerals on Adsorbed Nucleic Acid against UV Radiation: Possible Role in the Origin of Life. Int. J. Astrobiol.2004, 3 (1), 17-19. https://doi.org/10.1017/S147355040400179X.

(43) Strickler, K. M.; Fremier, A. K.; Goldberg, C. S. Quantifying Effects of UV-B, Temperature, and PH on EDNA Degradation in Aquatic Microcosms.Biol. Conserv. 2015, 183, 85-92. https://doi.org/10.1016/j.biocon.2014.11.038.

(44) Lewis, C. A.; Crayle, J.; Zhou, S.; Swanstrom, R.; Wolfenden, R. Cytosine Deamination and the Precipitous Decline of Spontaneous Mutation during Earth's History. Proc. Natl. Acad. Sci. 2016, 113 (29), 8194-8199. https://doi.org/10.1073/pnas.1607580113.

(45) Lance, R. F.; Klymus, K. E.; Richter, C. A.; Guan, X.; Farrington, H. L.; Carr, M. R.; Thompson, N.; Chapman, D.; Baerwaldt, K. L. Experimental Observations on the Decay of Environmental DNA from Bighead and Silver Carps.2017.

(46) Saito, T.; Doi, H. A Model and Simulation of the Influence of Temperature and Amplicon Length on Environmental DNA Degradation Rates: A Meta-Analysis Approach.Front. Ecol. Evol. 2021, 9, 623831. https://doi.org/10.3389/fevo.2021.623831. 
(47) Saito, T.; Doi, H. Degradation Modeling of Water Environmental DNA: Experiments on Multiple DNA Sources in Pond and Seawater. Environ. DNA2021, 3 (4), 850-860. https://doi.org/10.1002/edn3.192.

(48) Eichmiller, J. J.; Best, S. E.; Sorensen, P. W. Effects of Temperature and Trophic State on Degradation of Environmental DNA in Lake Water. Environ. Sci. Technol. 2016, 50 (4), 1859-1867. https://doi.org/10.1021/acs.est.5b05672.

(49) Shogren, A.; Tank, J. L.; Egan, S. P.; August, O.; Rosi, E. J.; Hanrahan, B. R.; Renshaw, M. A.; Gantz, C. A.; Bolster, D. Water Flow and Biofilm Cover Influence Environmental DNA (EDNA) Detection in Recirculating Streams.Environ. Sci. Technol. 2018. https://doi.org/10.1021/acs.est.8b01822.

(50) Grzyb, J.; Fraczek, K. Activity of Phosphohydrolytic Enzymes in Waters. Ecol. Chem. Eng. Chem. Inzynieria Ekol. A 2012, No. 6. https://doi.org/10.2428/ecea.2012.19(06)059.

(51) Kirtane, A.; Wieczorek, D.; Noji, T.; Baskin, L.; Ober, C.; Plosica, R.; Chenoweth, A.; Lynch, K.; Sassoubre, L. Quantification of Environmental DNA (EDNA) Shedding and Decay Rates for Three Commercially Harvested Fish Species and Comparison between EDNA Detection and Trawl Catches. Environ. DNA 2021, edn3.236. https://doi.org/10.1002/edn3.236.

(52) Kucherenko, A.; Herman, J. E.; Iii, E. M. E.; Urakawa, H. Terrestrial Snake Environmental DNA Accumulation and Degradation Dynamics and Its Environmental Application. Herpetologica 2018, 74 (1), 38-49. https://doi.org/10.1655/Herpetologica-D-16-00088.

(53) Morrissey, E. M.; McHugh, T. A.; Preteska, L.; Hayer, M.; Dijkstra, P.; Hungate, B. A.; Schwartz, E. Dynamics of Extracellular DNA Decomposition and Bacterial Community Composition in Soil. Soil Biol. Biochem. 2015,86, 42-49. https://doi.org/10.1016/j.soilbio.2015.03.020.

(54) Zulkefli, N. S.; Kim, K.-H.; Hwang, S.-J. Effects of Microbial Activity and Environmental Parameters on the Degradation of Extracellular Environmental DNA from a Eutrophic Lake. Int. J. Environ. Res. Public. Health 2019, 16 (18), 3339. https://doi.org/10.3390/ijerph16183339.

(55) Sirois, S. H.; Buckley, D. H. Factors Governing Extracellular DNA Degradation Dynamics in Soil. Environ. Microbiol. Rep. 2019, 11 (2), 173-184. https://doi.org/10.1111/1758-2229.12725.

(56) Bochove, K.; Bakker, F. T.; Beentjes, K. K.; Hemerik, L.; Vos, R. A.; Gravendeel, B. Organic Matter Reduces the Amount of Detectable Environmental DNA in Freshwater. Ecol. Evol. 2020, 10 (8), 3647-3654. https://doi.org/10.1002/ece3.6123.

(57) Jo, T.; Murakami, H.; Yamamoto, S.; Masuda, R.; Minamoto, T. Effect of Water Temperature and Fish Biomass on Environmental DNA Shedding, Degradation, and Size Distribution. Ecol. Evol. 2019. https://doi.org/10.1002/ece3.4802.

(58) Tsuji, S.; Ushio, M.; Sakurai, S.; Minamoto, T.; Yamanaka, H. Water Temperature-Dependent Degradation of Environmental DNA and Its Relation to Bacterial Abundance. PloS One 2017, 12 (4), e0176608.

(59) Siuda, W.; Chróst, R. J. Utilization of Selected Dissolved Organic Phosphorus Compounds by Bacteria in Lake Water under Non-Limiting Orthophosphate Conditions. Pol. J. Environ. Stud. 2001, 10 (6), 475483.

(60) Lever, M. A.; Torti, A.; Eickenbusch, P.; Michaud, A. B.; A antl-Temkiv, T.; JÃ rrensen, B. B. A Modular Method for the Extraction of DNA and RNA, and the Separation of DNA Pools from Diverse Environmental Sample Types.Front. Microbiol. 2015, 6. https://doi.org/10.3389/fmicb.2015.00476.

(61) Zinger, L.; Bonin, A.; Alsos, I. G.; Bálint, M.; Bik, H.; Boyer, F.; Chariton, A. A.; Creer, S.; Coissac, E.; Deagle, B. E.; De Barba, M.; Dickie, I. A.; Dumbrell, A. J.; Ficetola, G. F.; Fierer, N.; Fumagalli, L.; Gilbert, M. T. P.; Jarman, S.; Jumpponen, A.; Kauserud, H.; Orlando, L.; Pansu, J.; Pawlowski, J.; Tedersoo, L.; Thomsen, P. F.; Willerslev, E.; Taberlet, P. DNA Metabarcoding - Need for Robust Experimental Designs to Draw Sound Ecological Conclusions. Mol. Ecol. 2019,28, 1857-1862. https://doi.org/10.1111/mec.15060. 
(62) Hutchins, P.; Sepulveda, A. J.; Simantel, L. Time to Get Real with QPCR Controls: The Frequency of Sample Contamination and the Informative Power of Negative Controls in Environmental (e)DNA Studies. Authorea 2021. https://doi.org/10.22541/au.162559294.43104200/v1.

(63) Veldhoen, N.; Hobbs, J.; Ikonomou, G.; Hii, M.; Lesperance, M.; Helbing, C. C. Implementation of Novel Design Features for QPCR-Based EDNA Assessment.PLOS ONE 2016, 11 (11), e0164907. https://doi.org/10.1371/journal.pone.0164907.

(64) Turner, C. R.; Uy, K. L.; Everhart, R. C. Fish Environmental DNA Is More Concentrated in Aquatic Sediments than Surface Water. Biol. Conserv.2014, 183, 93-102. https://doi.org/10.1016/j.biocon.2014.11.017.

(65) Nicholson, A.; McIsaac, D.; MacDonald, C.; Gec, P.; Mason, B. E.; Rein, W.; Wrobel, J.; Boer, M.; Milián-Garcia, Y.; Hanner, R. H. An Analysis of Metadata Reporting in Freshwater Environmental DNA Research Calls for the Development of Best Practice Guidelines. Environ. DNA2020, 2 (3), 343-349. https://doi.org/10.1002/edn3.81. 